\section{The Need for Aseptic Barriers}

\section{To the Editor:}

As two of some 2,000 medical devices, the use of surgical gowns and drapes is simply one of those things that has evolved to be a standard of practice because of prudence. In 1952 it was first recognized that although the materials used for gowns and drapes were considered to provide an acceptable bacteriological barrier when dry, they lost whatever barrier capabilities they had once they became wet. ${ }^{1}$ And it is this principle that has become the very cornerstone of aseptic technique in terms of using gowns and drapes as aseptic barriers.

In 1975 the Association of Operating Room Nurses (AORN) commendably advanced the role of gown and drape materials in terms of their contribution to aseptic technique. Specifically, these materials were now required to have barrier capabilities, that is, to be resistant to blood and aqueous fluids. ${ }^{2}$ In acknowledging AORN's position, the American College of Surgeons' Committee on the Operating Room Environment called for the development of performance standards that would demonstrate the material's ability to perform satisfactorily. ${ }^{3}$ Although efforts to develop these performance standards failed, there was a consensus of opinion that readily permeable fabrics, such as the traditional all cotton Type 140 loosely woven muslin, could not be considered satisfactory aseptic barriers. ${ }^{4}$
Subsequently, Moylan published a study concluding that the use of nonwoven disposable barrier surgical gowns and drapes were responsible for a reduction in the rate of surgical wound infection (SWI). ${ }^{5}$ Since its publication, this study has been frequently referenced by those supporting the use of barrier materials. Their position has recently been reinforced by the publication of a second study by Moylan. ${ }^{6}$

Overlooked in the interim, however, are the results of two other independent studies, one by Garibaldi, ${ }^{7}$ the other by Schaaf. ${ }^{8}$ Each investigator found no difference in the SWI rates when using a (disposable) barrier gown and drape system compared with the rate reported with a (reusable) nonbarrier system.

With the disclosure of these two studies challenging the influence of barrier materials on SWI rates, the question now is whether or not the infection control community is prepared to reconsider and reassess an aseptic practice that has been recommended for over a decade. It could well be that a departure from the universal application of the barrier principle, such as with general clean and clean-contaminated procedures, may not compromise the quality of care, while proving at the same time to be economically advantageous as well.

A thought-provoking notion to say the least.

\section{REFERENCES}

1. Beck WC, Collette TA: False faith in the surgeon's gown and surgical drape. Am J Surg 1952; 83:125.
2. AORN Standards for Wearing Apparel, Draping and Gowning Materials. AORN J 1975; $21: 594$.

3. Bernard HR, Beck WC: Operating room barriersIdealism, practicality and the future. Bull Am Coll Surg 1975; 60:16.

4. Beck WC, Meeker MR: Demise of aseptic banier committee: Success and failure. AORN / 1983 38:384-388.

5. Moylan JA, Kennedy B: The importance of gown and drape barriers in the prevention of wound infection. Surg Gynecol Obstet 1980; 151:465-470.

6. Moylan JA, Fitzpatrick KT, Davenport KE: Reducing wound infections. Arch Surg 1987; 122:152-157.

7. Garibaldi RA, Maglio S, Lerer T, et al: Comparison of nonwoven and woven gowns and drape fabric to prevent intraoperative wound contamination and postoperative infection. Am I Surg 1986 ; 152:505-509.

8. Schaaff D, Rausch C, Pappas S: Single-use nonwoven gowns and drapes: No effect on postoperative wound infection rate. Abstract 1033, 26th Interscience Conference on Antimicrobial Agents and Chemotherapy, 1986, New Orleans, Louisiana.

Nathan L. Belkin, PhD

Vice President Superior Surgical Mfg. Co., Inc. Seminole, Florida

\section{An Appropriate Category of Isolation for Antibiotic-Resistant Organisms}

\section{To the Editor:}

Colonization of patients with methicillin-resistant Staphylococcus aureus (MRSA) or aminoglycoside-resistant, gram-negative organisms can, for two reasons, be as dangerous as infection. First, colonizing organisms can be as easily transmitted between patients and staff, and second, colonization often precedes infection. This condition was demonstrated very clearly 
by Walsh et al in a three-year prospective study during which three peaks of MRSA colonization occurred, each of which was followed by an outbreak of infection. ${ }^{1}$

Others have described similar situations. In many cases, outbreaks have "been prolonged in spite of institution of "Contact" or "Strict Isolation." The failure of these types of isolation to halt outbreaks is not surprising and we have, therefore, developed a new, more appropriate category-"Isolation for Resistant Organisms" (IRO) (Figure). The reasons for failure of Contact Isolation are that gloves are recommended only for touching the infected area or secretions, which does not take into consideration that the patient may have become colonized in areas other than the original site. ${ }^{2}$ And, Staphylococcus aureus can persist in the environment for long periods, even with good cleaning practices, thus the clothing of staff may become contaminated and spread the organisms. ${ }^{3}$ On Strict Isolation, gowns, gloves, and masks are required, but all types of isolation are discontinued when the infection clears, which may be premature in these cases if colonization persists in old and new sites.

Our new category also includes patients with infections that are not usually considered transmissible and would not normally require isolation, such as bacteremia, endocarditis, asymptomatic bacteriuria, and pneumonia. ${ }^{4}$ There is no reason to believe that these organisms are any less likely to colonize the patient in areas such as the skin or the nares, from which they can be transmitted.

The new isolation requirements are stringent. Patients require a private room, and if the respiratory tract is involved (other than the nares), negative pressure is required. All hospital personnel who enter the room must always wear a gown and gloves, even if they only intend to speak to the patient. The reason for these strict measures is that MRSA exists in the patient's environment and even though there may be no intent to have direct contact with the patient, the organism can be acquired by personnel when touching the patient's bed, furniture, bathroom, and equipment. In one hospital, MRSA was cultured from 14 environmental sources,

\section{Isolation for}

Resistant Organisms (Colonization/Infection) Visitors-Report to Nurses' Station Before Entering Room

- PRIVATE ROOM REQUIRED.

- GOWNS-Must be worn by everyone entering room.

- GLOVES-Must be worn by all hospital personnel before entering.

- MASKS-Required only if respiratory tract is involved.

- ARTICLES - Must be bagged or adequately disinfected before removing from room.

- HANDS - Must be washed by everyone, even if gloves were worn.

- VISITORS-Need not wear gloves, but must be instructed to wash hands before leaving the room. VISITORS - Should remain in the patient's room and not go to any other hospital area.

\section{NOTIFY INFECTION CONTROL BEFORE ISOLATION IS DISCONTINUED}

13048-4 5/84 rev. $1 / 87$

including a blood pressure cuff, charts, and telephones, after all patients had been discharged and the rooms had been terminally cleaned. ${ }^{3}$

Masks are only required if resistant organisms have been cultured from the patient's respiratory tract, as personnel may then also become colonized via the airborne route. All articles in the patient's room are considered contaminated, as they may have been handled by hospital personnel or the patient. These articles must be disinfected on site or decontaminated in Central Service via gas or steam processing.

Hands must be washed after removal of the protective apparel before leaving the room. Trash from the patient's room should be handled in the same manner as other garbage from isolation rooms. This procedure may vary from state to state.

We do not believe that all visitors need to wear gloves or masks as long as they do not intend to visit other hospital areas and provided they wash their hands before leaving the room. This provides nurses with the opportunity to educate both the visitors and the patients about transmission of colonizing or infecting organisms. Nurses can further explain why some persons, such as healthy visitors, are not at risk of being infected with the organisms, while patients may have severe 
risk factors, such as incisions, indwelling IV and urinary catheters, and tracheostomy tubes.

Before a patient can come off this type of isolation, certain criteria must be met. The resistant organism must no longer be present at the site, whether or not the infection (eg, the drainage) has cleared. If a wound was infected but has now healed, the skin at the site must still be cultured. In addition, MRSA especially, may have colonized the skin or mucous membranes of the patient. Although one study found that in the presence of a tracheostomy, the site was more often positive than the nares. ${ }^{1}$ We require a culture of both anterior nares to be negative for the resistant organism before the patient can be taken off isolation. The other requirement is that infection control personnel must be consulted before the patient comes off isolation, and we check that the culture results are final reports, not preliminary or interim findings, before permitting the discontinuance of isolation. Preliminary reports have occasionally been changed later and the extra day is well worth the wait.

Although the new category of Isolation for Antibiotic-Resistant Organisms is very demanding on the staff and costly for the institution, we have found that in a large institution such as ours (533 beds), it has prevented premature removal of patients from other types of isolation when their infection, but not necessarily their colonization, cleared. We believe keeping patients on this rather stringent kind of isolation has curtailed the spread, especially of MRSA, because personnel are anxious to avoid new cases, and are thus very strict in enforcing the necessary precautionary measures for themselves and other hospital personnel.

\section{REFERENCES}

1. Walsh TJ, Vlahov D, Hansen SL, et al: Prospective microbiologic surveillance in control of nosocomial methicillin-resistant Staphylococcus aureus. Infect Control 1987; 8:7-14.

2. Garner J, Simmons BP: Guidelines for Isolation Precautions in Hospitals. Atlanta, Centers for Disease Control, 1983.

3. Bitar CM, Mayhall CG, Lamb VA, et al: Outbreak due to methicillin- and rifampin-resistant Staphylococcus aureus: Epidemiology and eradication of the resistant strain from the hospital. Infect Control $1987 ; 8: 15-23$

4. Craig C: How should bacteremic MRSA patients and colonized employees be treated? Hosp Infect Control 1987; 14:94-95.

Inge Gurevich, RN, MA, CIC Barbara Yannelli, RN, CIC Burke A. Cunha, MD

Infection Control Section Winthrop-University Hospital Mineola, New York

\section{HIV Infection per Needlestick in Health Care Workers}

\section{To the Editor:}

As an active participant in one ${ }^{1}$ of several studies ${ }^{2-6}$ designed to examine the actual risk of transmission of human immunodeficiency virus (HIV) through contaminated needlesticks in a nosocomial setting, I am concerned that the relative risk published to date ${ }^{1,6}$ has been based on an assumption that all patients who are $\mathrm{HIV}$-antibody positive are viremic and capable of transmitting HIV per needlestick to health care personnel.

As pointed out in a recent survey ${ }^{7}$ of 39 HIV-antibody positive individuals who were in various clinical stages of infection, almost half (46.2\%) of these patients lacked evidence of viremia, based on serum and peripheral mononuclear cell cultures. If we assume that almost half of the health care workers who have been enrolled to date in needlestick exposure studies were not exposed to blood containing , HIV, then our denominators used to calculate risk should be halved and the relative risk should be doubled.

At present, I worry that the published data foster a false sense of security, not only in health care workers but also in investigators participating in these epidemiologic studies. In this vein, such studies might be terminated before true relative risk can be obtained.

The future capability to perform more extensive virologic examinations of specimens routinely should allow us to categorize HIV-infected individuals more definitively into certain exposure risk groups, much like what has already been done in patients with hepatitis B. ${ }^{8}$

While the present HIV/needlestick studies provide us with relative risk based on HIV-antibody positivity, I think the ultimate goal of these studies should be to stratify this risk.

Certainly, these studies have already provided us with at least one valuable, and yet, not unexpected revelationthat a large portion of the accidental exposures that have occurred could have been prevented had routine infection control policies been followed. We must take this strong message to our fellow health care professionals.

\section{REFERENCES}

1. McCray E: The Cooperative Needlestick Surveillance Group: Occupational risk of the acquired immunodeficiency syndrome among health care workers. N Engl J Med 1986; 314:1127-1132.

2. Hirsch MS, Wormser GP, Schooley RT, et al: Risk of nosocomial infection with human $\mathrm{T}$ cell lymphotropic virus III (HTLV-III). $N$ Engl J Med 1985 ; 312:1-4.

3. Weiss SH, Saxinger WC, Rechtman D, et al: HTLVIII infection among health care workers: Association with needlestick injuries. JAMA 1985; 254:2089-2093.

4. Kuhls TL, Viker S, Parris NB, et al: A prospective cohort study of the occupational risk of AIDS and AIDS-related infections in health care personnel. Clin Res $1986 ; 34: 124 A$. 